\title{
From Number Crunching To Organizational Leadership: Can Distance Education Adequately Handle The Range Of Graduate Business Classes?
}

Daniel M. Gropper, (Email: groppdm@auburn.edu), Auburn University William S. Schaninger, Jr., McKinsey and Company, London, England Robert E. Niebuhr, Tennessee Technological University

\begin{abstract}
With distance education delivery technology improving almost continuously, many Universities are seeking out distance education opportunities to expand their programs. We seek to examine the effectiveness of the distance delivery approach across the range of types of courses offered in $M B A$ programs - from the organizational leadership classes to the more quantitative "number crunching" classes. Student performance in several types of MBA courses was evaluated as a result of presenting the same material on-campus (synchronously) and via distance education (asynchronously) in three different kinds of graduate business courses; a course in organizational leadership, an analytical course in managerial economics, and a quantitative methods course. A number of individual variables (e.g., GMAT scores, undergraduate GPA) were included as explanatory factors regarding student performance. Using multiple hierarchical regression analysis, the asynchronous distance delivery model was determined to have no adverse impact on student performance across all of these different types of MBA courses, indicating that indeed distance education techniques can adequately handle this broad range of graduate business classes.
\end{abstract}

\section{INTRODUCTION}

(Lenzner, 1997):
(Leter Drucker offered the following observation regarding higher education in the United States

"Thirty years from now the big university campuses will be relics. Universities won't survive. It's as large a change as when we got the printed book...Higher education is in deep crisis...Already we are beginning to deliver more lectures ... via satellite or two-way video at a fraction of the cost. The college won't survive as a residential institution (p.126).”

What could possibly be occurring on campuses nationwide that would engender a comparison with the impact of the introduction of the printed word? What would elicit such an apocalyptic prophecy from a modern day business legend? The change that Drucker was addressing was the mainstream implementation of distance education.

With distance education delivery technology improving rapidly, universities are seeking out opportunities to reach parts of the population previously inaccessible to them (Blumenstyk, 1999b). While some schools have arisen as exclusively distance education based institutions, others are expanding their existing offerings. Even traditional brick and mortar institutions such as Auburn University, Duke University, Indiana University, Johns Hopkins University, the University of Maryland, Purdue University, Queen's University, the University of 
Pennsylvania, and Syracuse University have embraced the distance learning approach (Potashnik \& Capper, 1998; Webster \& Hackley, 1997).

The rapid emergence of accredited schools in the distance learning environment has given this approach to higher education greater legitimacy. For the last several years, AACSB International, the prestigious accrediting group for Colleges of Business, has been offering meetings focused on distance education practices. By 1995, 33\% of all higher education institutions offered some form of distance education (Kirk \& Bartelstein, 1999). In 1997, 1000 institutions of higher learning offered distance education courses (Lozado, 1997). By 1998, 85\% reported that they were currently offering or planning to offer distance education courses (National Center, 1998). In a 1999 AACSB study, it was determined that almost $40 \%$ of the responding colleges of business were already offering distance learning degree programs (AACSB, 1999). Harris (1999) claims that in the next decade, it is expected that the demand for distance based higher education will increase by at least $30 \%$. Increasingly, for individuals to remain fully employed in the economy, they need post-secondary education or training (Harris, 1999).

The purpose of this paper is four-fold: 1) To identify a common definition of distance education; 2) To empirically explore the impact asynchronous distance delivery of educational material has on student outcomes across the major types of different courses offered in MBA programs; 3) To explore if women experience outcomes similar to men in the distance education classes; and 4) To determine if relevant demographic variables are capable of predicting student outcomes in a distance-learning environment.

While distance education has been carried out over the years by various technological means (audiotape, television, satellite downlinks, videotape, DVD, Internet) the definition of the concept of distance education has remained relatively stable over time. Clark and Verduin, Jr. (1989) attributed the 1960's conceptualization to Otto Peters who popularized distance education in Europe. His definition asserts that distance education is formal study where the instructor and student are separated during the delivery of the material. Holmberg (1985; as cited in Barket \& Holley, 1996) identified distance education as "various forms of study at all levels which are not under the continuous, immediate supervision of a tutor... nevertheless, benefit from the planning, guidance, and tuition of a tutorial organization (p.2)". Guerrero and Kelly (1998) established three themes from the definitions of distance education they found; "(1) learning involves a geographical distance between the instructor and learner, (2) opportunity for face to face interactive communication between the instructor and learner is more limited than in the traditional classroom, and (3) some type of medium is involved to span the geographical distance between the teacher and the learner. (p.31)". Hickman (1999) embraces brevity when describing distance education as an organized learning activity that occurs away from the setting where it (the learning) is usually conducted. Finally, Davey (1999) suggests that distance education is occurring any time that the instructor and student are separated by time or distance. Given this background, the following definition of distance education is offered:

Distance education is a form of knowledge transfer that occurs without regard to temporal or proximal synchronicity. The instructor / knowledge provider is able to deliver content in an asynchronous fashion that facilitates the convenient accessing of the material by the student / learner. The ingredient that facilitates these transfers is a technological medium (TV, CD/DVD, two-way video, videotape, Internet, etc.) that is appropriate for the depth and breadth of the content delivered.

The literature that exists on distance education is largely anecdotal and opinion based with relatively little empirical work (Merisotis \& Phipps, 1999). The empirical work that does exist is largely positive towards distance education (for an in-depth discussion of the relative merits of much of this work see Merisotis \& Phipps, 1999). However, there remains a significant stream of literature that is critical of distance-based, higher education. In response to this schism, both positive and negative opinions will be reviewed before establishing research questions.

One of the most salient reasons for why distance education is attractive to educational institution administrators is to realize possible economies of scale. Distance education programs can use existing resources to expand the universities' ability to serve a much wider audience within the populace (Hickman, 1999). The opportunity to provide education to underserved portions of the population is often both an institutional and public policy issue. By implementing a distance education program, both issues can be addressed. The use of these 
technologies provides the university with the tools to simultaneously reach large numbers of students without significant investment in additional land or building space (Guerrero \& Miller, 1998). Further, administrators can view the initiation of a distance education program as a win-win opportunity for them. By starting the program, the institution will serve portions of the market not previously addressed by the traditional on-campus programs. In addition, the program will force students to become comfortable with technologies (email, video, etc.) that are necessary for success in the modern business environment (Webster \& Hackley, 1997).

Farber (1998) reports that people educated in a traditional college environment tend to be more flexible, open to new ideas, tolerant of ambiguity, more socially adjusted than the norm, and comfortable discussing abstract concepts. In addition, these people were found to be more oriented towards rational decision making patterns, willing to get involved in politics, appreciative of the arts, and internally motivated regarding work. While these are all wonderful attributes, can we reasonably expect the same from individuals who get the educational experience in a non-residential manner?

Thomas Russell (1997) would suggest yes. He maintains a web site that details the findings of 355 papers, manuscripts, and projects that concluded there is "no significant difference" in student outcomes between traditional face-to-face instruction and distance education. While there are some significant methodological issues with many of the empirical papers (e.g., the Wang and Newlin (2000) study of web instruction versus classroom instruction did not control for individual differences), Russell's extensive compilation of studies makes a compelling argument for the finding of no adverse impact on student performance from distance learning approaches.

As stated earlier, there are some very ardent opponents to the expansion of distance education. It would be easy to dismiss many of these criticisms out of hand by claiming that professional academics (from whom the majority of the criticisms originate) are instilled with a sense of self-preservation that pervades thinking on this issue. However, to do so would be to ignore an opportunity to honestly assess distance education programs with a critical eye.

The majority of criticism is derived from anecdotal or opinion pieces that tend to focus on the credibility of distance education (Potashnik \& Capper, 1998) and on the issue of instructor-student interaction. Some scholars still believe that a distance-based program is inferior (Clark, T. \& Verduin, J. 1989; Walling, 1996). By our definition, we describe distance learning as something that is not bound by proximal or temporal synchronicity. Thus, the instructor and student may have very little "live", one on one interaction. Some academics assess distance learning as merely receiving knowledge because it can be done, ostensibly, without the interaction and support of the faculty (Blumenstyk, 1997). Certainly one of the drawbacks to any of the asynchronous delivery mechanisms is a lack of personal interaction with the instructor and cohort group (Guerrero \& Miller, 1998). While the technology available can leverage the instructors' time and make him/her more productive, it cannot replace time spent with students (Merisotis \& Phipps, 1999). In addition, there are other complaints about distance learning programs. One is that the student may feel isolated because they do not have steady contact with a cohort group. The other is that in research based distance education programs, the ability to gain access to a library is critical and may be less available to distance graduate students (Kirk \& Bartelstein, 1999).

It has been purported that women do not do as well in distance education programs because they do not like the distance setting. Specifically, women have been assigned the label of not liking to communicate through email, of not liking to express opinions in group settings, and needing an extremely collegial atmosphere (Koch, 1998; Blumenstyk, 1997). Our sample allows us to explore this issue, at least to the extent that it affects performance among the several hundred students in these classes. Empirical literature that has looked expressly at woman has found cases where the women performed at or above their male companions (Blumenstyk, 1997, Hancock, 1999). While there are many opinions on the subject of distance learning, this paper will focus specifically on outcomes, i.e., the performance of students in a distance-learning environment contrasted with the performance of students in a traditional campus approach. The following research questions will be addressed:

R1 - Do distance education students perform as well as on-campus students?

R2 - Do woman perform at a disproportionately lower level in the distance education setting? 
R3 - Do the demographic variables of age, GMAT score, undergraduate GPA, undergraduate major, undergraduate school, etc. contribute to predicting student performance?

R4 - Does the distance delivery process differentially affect learning outcomes in the alternative types of course material presented in various elements of an MBA program - from the quantitative skills classes to the "soft skills" classes?

\section{METHODS}

\section{Data}

Demographic data for this project were collected from the admission records of 296 graduate business (MBA) students enrolled in a large land-grant university in the southeastern United States. For this sample, 67 percent were male and 33 percent female. Slightly more than half (52\%) of the students were traditional, on-campus students while $48 \%$ were in a distance-based program. The distance-based program had been in existence for over five years and consisted primarily of providing the same course lectures via videotape to the distance students. These distance students received the same textbooks, cases, handouts, and other materials as the campus students and completed the same assignments. Proctored exams, when required, were typically administered by training officers at the distance student's workplace. MBA program policy is that all distance student assignments be completed within two weeks of the time that they were due on campus. All programs at this University's College of Business have been reviewed as part of the reaccreditation process by AACSB International, including all MBA program options, and reaccreditation was granted.

In this study, we examined groups of students from three different types of MBA courses; a quantitative methods course, a managerial economics course, and an organizational leadership course. The faculty were the same for both the campus and distance delivery sections of the three courses; the on-campus course lectures and discussions were videotaped and sent to the distance students. Faculty were available by telephone or email if the distance-based students had questions on course content or other matters. The students' age ranged from 21 to 56 with a mean age of 27. GMAT scores ranged from 400 to 760 with a mean score of 553. A more detailed exploration of the demographic breakdown of this sample is provided in Tables 1 and 2. Descriptive statistics and correlations were calculated for all variables utilized and are presented in Table 1 . Table 2 indicates that the distance MBA students differed from the campus MBA students in several aspects. They were older, with more work experience and also had higher average GMAT scores.

The data utilized in this study were collected from one quarter to four years after the students had taken the courses. Grade data were collected only when the instructor taught the course to the distance-based students and the on-campus students at the same time. MBA program admission files were accessed to provide the demographic data for each student. Once the grade data was matched to the demographic data, any identifying features of the data were removed.

\section{Independent Variables}

\section{Gender}

This variable is coded as a binary (dummy) variable. A value of 0 indicates a male respondent and 1 indicates a female respondent. This is a demographic control variable, which has previously been found to be significant (Hancock, 1999).

Age

This continuous variable denotes the age of the respondent at the time they applied to the program. This is another demographic control variable. 


\begin{tabular}{|c|c|c|c|c|c|c|c|c|c|c|c|c|c|c|c|c|c|c|}
\hline & Variable & Mean & $\begin{array}{l}\text { Std. } \\
\text { Dev. }\end{array}$ & 1 & 2 & 3 & 4 & 5 & 6 & 7 & 8 & 9 & 10 & 11 & 12 & 13 & 14 & 15 \\
\hline 1 & Gender & 0.3277 & 0.4702 & 1 & & & & & & & & & & & & & & \\
\hline 2 & Age & 27.3253 & 5.8623 & -0.17 & 1 & & & & & & & & & & & & & \\
\hline 3 & GMAT & 553.4589 & 75.5736 & -0.28 & 0.053 & 1 & & & & & & & & & & & & \\
\hline 4 & Undergrad GPA & 3.1281 & 0.3833 & 0.167 & -0.003 & -0.017 & 1 & & & & & & & & & & & \\
\hline 5 & Undergrad Major & 1.0272 & 1.0512 & 0.093 & -0.022 & -0.18 & 0.01 & 1 & & & & & & & & & & \\
\hline 6 & Work Years & 4.585 & 5.5528 & -0.144 & 0.892 & 0.078 & -0.024 & -0.014 & 1 & & & & & & & & & \\
\hline 7 & VIDEO/CAMPUS & 0.5169 & 0.5006 & 0.171 & -0.437 & -0.167 & 0.019 & 0.123 & -0.45 & 1 & & & & & & & & \\
\hline 8 & GMAT-Q \% & 57.4362 & 23.9239 & -0.29 & -0.009 & 0.84 & -0.074 & -0.238 & 0.016 & -0.124 & 1 & & & & & & & \\
\hline 9 & GMAT-V\% & 64.4645 & 20.2666 & -0.091 & 0.054 & 0.726 & 0.046 & 0.049 & 0.074 & -0.079 & 0.331 & 1 & & & & & & \\
\hline 10 & GMAT-Total $\%$ & 64.2801 & 21.4833 & -0.246 & 0.022 & 0.96 & -0.046 & -0.142 & 0.048 & -0.14 & 0.826 & 0.729 & 1 & & & & & \\
\hline 11 & UGRAD School & 2.914 & 1.9489 & -0.055 & 0.126 & -0.111 & 0.142 & 0.147 & 0.11 & -0.102 & -0.106 & -0.045 & -0.121 & 1 & & & & \\
\hline 12 & $\begin{array}{l}\text { Quarter } \\
\text { Soft-skills Course }\end{array}$ & 4.0608 & 2.1096 & 0.048 & 0.075 & 0.129 & 0.014 & -0.247 & 0.066 & -0.043 & 0.154 & 0.022 & 0.114 & -0.008 & 1 & & & \\
\hline 13 & $\begin{array}{l}\text { Grade } \\
\text { Analytical Course }\end{array}$ & $2.63 \mathrm{E}-15$ & 1 & 0.118 & 0.148 & -0.028 & 0.171 & -0.134 & 0.126 & -0.232 & -0.006 & -0.134 & -0.018 & 0.177 & 0.030 & 1 & & \\
\hline 14 & $\begin{array}{l}\text { Grade } \\
\text { Quantitative Course }\end{array}$ & $1.57 \mathrm{E}-15$ & 1 & 0.042 & 0.143 & 0.218 & 0.364 & 0.142 & 0.143 & -0.094 & 0.291 & 0.081 & 0.232 & -0.003 & & & 1 & \\
\hline 15 & Grade & $8.13 \mathrm{E}-16$ & 1 & 0.074 & -0.02 & 0.263 & 0.107 & -0.231 & 0.025 & 0.064 & 0.274 & 0.095 & 0.226 & -0.222 & 0.321 & & & 1 \\
\hline
\end{tabular}

Table 2 - Group Means for Comparison of Campus and Distance-Based Students

\begin{tabular}{|l|l|l|l|l|l|l|l|}
\hline Variable & Total & Campus & Distance & \multirow{2}{*}{ F } \\
\cline { 2 - 9 } & $\mathrm{n}$ & Mean & $\mathrm{n}$ & Mean & $\mathrm{N}$ & Mean & \\
\hline Age & 338 & 27.7 & 161 & 25.0 & 177 & 30.2 & $77.1^{*}$ \\
\hline GMAT & 336 & 555 & 163 & 540 & 173 & 569 & $13.2^{*}$ \\
\hline Undergraduate GPA & 331 & 3.14 & 158 & 3.15 & 173 & 3.12 & .5 \\
\hline Years of work experience & 342 & 4.7 & 168 & 2.2 & 174 & 7.2 & $83.5^{*}$ \\
\hline Soft skills course grade & 183 & 84.4 & 96 & 82.3 & 87 & 86.7 & $11.2^{*}$ \\
\hline Analytical course grade & 88 & 90.8 & 49 & 90.5 & 39 & 91.1 & .5 \\
\hline Quantitative course grade & 126 & 86.6 & 62 & 87.3 & 64 & 86.0 & .5 \\
\hline
\end{tabular}

$* \mathrm{p}<.001$

\section{Work Years}

This continuous variable describes the number of years of work experience the student had at the time of their admission to the MBA program, consistent with other researchers (Adams and Hancock, 2000; Dreher and Ryan, 2000).

\section{GMAT}

The Graduate Management Admissions Test (GMAT) is the verbal and quantitative reasoning test required for admission to the MBA program, which has been found to be a significant predictor of student success, although not without some difference of opinion (see, for example, Hancock, 1999 and Thayer and Khalat, 1998). While the total GMAT score could be used, our interest in examining performance in different class types led us to use the separate scores on the verbal and quantitative portions of the GMAT, as indicated below. 
GMAT-V\%

This is the percentile ranking for the student's verbal portion of the GMAT. This is used as a control variable to reflect academic ability.

GMAT-Q\%

This is the percentile ranking for the student's quantitative portion of the GMAT. This is used as a control variable, particularly as it may reflect academic ability related to the quantitative material.

\section{Undergraduate GPA}

This is undergraduate grade point average. The values here could range from 0 to 4.0. This was also utilized as a control variable related to academic ability.

\section{Undergraduate Major}

This variable is a categorical variable intended to address the type of undergraduate major the respondent had. The variable is coded in an ordinal fashion $(0=$ engineering, $1=$ math/science, $2=$ business, $3=$ liberal arts, and $4=$ other). An ordinal approach to coding was chosen for this data in an effort to depict a perceived relationship between undergraduate major and quantitative orientation. This variable was created under the assumption that engineering students were in general, more quantitatively oriented. This is consistent with other researchers attempting to model student performance while controlling for individual student differences (Caudill \& Gropper, 1991).

\section{School Code}

This ordinal variable is intended to capture the type of undergraduate institution the student attended. The categories correspond to the Carnegie Foundation classification system for higher education institutions. As coded here, $1=$ Research 1, 2= Research 2, 3= Doctoral 1, 4= Doctoral 2, 5= Comprehensive 1, $6=$ Comprehensive 2, $7=$ Baccalaureate 1 , and $8=$ Baccalaureate 2 .

\section{Distance/Campus}

This variable is categorical. In this case, 1 denotes that the student received the course in a distance learning/asynchronous format (one-way video) and 0 denotes that the student received instruction in a traditional format (on-campus lecture).

\section{Criterion Variables}

The use of grades as a criterion is well established in this literature stream (Burton, 1998; National Center, 1998). Hickman (1999) reported that determining quality in distance education programs was generally accomplished by measuring grades. The use of course grades is supported by Farber (1998) who acknowledges that measurable competence (as represented by grades) often represents the core of the course. While the grade alone does not capture the richness of student achievement in its entirety, it is a more valid measure of student outcomes than anecdotal comments provided in many previous studies. For each of the following three types of course testing designs the campus and distance students had the same instructor, same course content, and the same course grading criteria. The difference between the instructional pedagogy is that the campus students had experienced synchronous content delivery versus the distance students receiving asynchronous content delivery. 


\section{Organizational Leadership Course Average}

This course is primarily focused on analyzing and applying the principles of organizational change to a variety of case-based scenarios. It has little to no quantitative expectations. The outcome variable here is test average. This variable has been standardized to address issues regarding grade inflation and range restriction.

\section{Analytical Course Test Average}

This course is primarily focused on the principles of economic theory applied to managing organizations. It encompasses both a conceptual and quantitative component. The outcome variable here is the course test average from a series of essay question tests. This variable has been standardized to address issues regarding grade inflation and range restriction.

\section{Quantitative Course Test Average}

This course is focused primarily on the fundamentals of statistical analysis. There is virtually no conceptual component to this course; it is almost exclusively driven by quantitative expectations. The outcome variable for this course is test average. This variable has been standardized to address issues regarding grade inflation and range restriction.

\section{METHODOLOGICAL CONCERNS}

In "What's the Difference", Merisotis and Phipps (1999) review the current (1990's) empirical literature that has examined the outcomes of distance education programs. The authors were able to clearly identify several shortcomings in the research. This paper's research design is intended to address most of the issues brought out in the Merisotis and Phipps report.

Controlling for extraneous variables was identified as the primary shortcoming in the existing literature. For this study we have included ten demographic variables to address this issue. Clearly, if variance is being accounted for by individual differences, that point must be addressed prior to making attributions about the relative merits (or lack thereof) of distance education.

Not randomly assigning subjects was identified as a shortcoming in the existing literature. The data for this study were taken from classes that received exactly the same pedagogy and course expectations. The courses included in this study were always taught and taped on campus for distribution to the distance-based students. While not randomly assigned, the assumption here is that with appropriate controlling for extraneous variables and by insuring that the delivery mechanism was the same, this study can avoid the confounds identified in the Merisotis and Phipps (1999) work.

Not controlling for reactive effects was also identified as a shortcoming in the existing literature. Specifically, "Novelty Effect" and "John Henry Effect" were mentioned. It is important to note that data collection occurred well after the grade sheets being turned in by the instructors. Thus, there was no experiment for which the students would change their behavior since they were unaware of any research that might be done.

\section{ANALYSIS}

Hierarchical regression was utilized as the primary analysis procedure. Criterion variables were predicted individually. All demographic variables were loaded in the initial block, with the predictor of interest being loaded last and in a separate block to establish an overall $\mathrm{R}^{2}$ for the model as well as an incremental $\mathrm{R}^{2}$ for the predictor of interest. In the case of Research Question 2, the use of an interaction term appeared appropriate and one was calculated for use in the regression equation. In this analysis, the interaction term was added in as the last predictor. It was regressed against the three criterions individually. In addition, the beta weights (in the full models) for each demographic variable provided the information necessary to answer that research question. It should be noted that 
several of the variables collected were not utilized in the final regression models due to problems with multicollinearity.

\section{RESULTS}

Research Question 1: Do distance education students perform as well as on-campus students?

Without any consideration for control variables, Table 2 did indicate that the distance students achieved a higher average grade in the case-based course. Table 3 presents the results from the hierarchical regression analysis for the three criterion variables. It appears that in this sample, after accounting for demographic variables, distance education students fare as well as traditional students regardless of the course content. For the case-based course grade the full model was non-significant $(\mathrm{F}=1.213 ; \mathrm{p}=.298)$ and the distance education (distance/campus) variable was not significant. For the essay-based course the overall model was significant $(\mathrm{F}=2.703 ; \mathrm{p}=.013)$ but the distance/campus variable was not significant. Finally, with regard to the quantitative course, the overall model is significant $(\mathrm{F}=3.719 ; \mathrm{p}=.001)$ but the distance/campus variable was not significant. These results are consistent with numerous other studies (Koch, 1998; Russell, 1998; Walling, 1996; and Clark \& Verduin, 1996). In all of those pieces, the distance learners were found to have done as well or exceeded the traditional learners.

Table 3 - Multiple Hierarchical Regressions

\begin{tabular}{|c|c|c|c|c|c|c|}
\hline \multirow[b]{2}{*}{ Variable } & \multicolumn{2}{|c|}{ Soft skills Course } & \multicolumn{2}{|c|}{ Analytical Course } & \multicolumn{2}{|c|}{ Quantitative Course } \\
\hline & $\beta$ & Sig. & $\mathrm{B}$ & Sig. & $\beta$ & Sig. \\
\hline (Constant) & & 0.434 & & 0.000 & & 0.007 \\
\hline Gender & 0.123 & 0.280 & 0.117 & 0.373 & 0.182 & 0.069 \\
\hline Undergrad GPA & 0.131 & 0.243 & 0.334 & 0.006 & 0.125 & 0.188 \\
\hline Undergrad Major & -0.044 & 0.718 & 0.115 & 0.373 & -0.212 & 0.032 \\
\hline Work Years & 0.011 & 0.934 & 0.133 & 0.307 & 0.145 & 0.171 \\
\hline GMAT-Q \% & 0.042 & 0.735 & 0.254 & 0.074 & 0.263 & 0.017 \\
\hline GMAT-V\% & -0.101 & 0.398 & 0.078 & 0.528 & 0.046 & 0.657 \\
\hline Undergrad School & 0.134 & 0.222 & -0.017 & 0.888 & -0.123 & 0.208 \\
\hline Quarter & 0.009 & 0.936 & & & 0.274 & 0.005 \\
\hline \multirow[t]{4}{*}{ Distance/Campus } & -0.204 & 0.139 & 0.006 & 0.970 & 0.148 & 0.166 \\
\hline & $\mathrm{F}$ & 1.23 & $\mathrm{~F}$ & 2.703 & $\mathrm{~F}$ & 3.719 \\
\hline & $\mathrm{R}^{2}$ & 0.113 & $\mathrm{R}^{2}$ & 0.268 & $\mathrm{R}^{2}$ & 0.283 \\
\hline & Sig & 0.298 & Sig & 0.013 & Sig & 0.001 \\
\hline
\end{tabular}

Research Question 2: Do women perform at a disproportionately lower level in the distance education setting?

No, they do not. The interaction term between gender and the distance education variable was insignificant for each criterion. Table 4 presents the results of the hierarchical regression models that utilized interaction terms to explore this question for all three criterion variables. With respect to the case-based class the interaction term was not significant $(\mathrm{p}=.58)$. For the essay-based class the interaction term also produced non-significant results $(\mathrm{p}=.323)$. Finally, in the quantitative class, the interaction term was also insignificant $(\mathrm{p}=.706)$. Apparently, the issues concerning negative female reaction to distance learning did not arise in our sample, or if they did, it was not to a point where it influenced performance. 
Table 4 - Multiple Hierarchical Regression Testing for Interaction Effect

\begin{tabular}{|c|c|c|c|c|c|c|}
\hline & \multicolumn{2}{|c|}{ Soft-skills Course } & \multicolumn{2}{|c|}{ Analytical Course } & \multicolumn{2}{|c|}{ Quantitative Course } \\
\hline & $\beta$ & Sig. & $\beta$ & Sig. & $\beta$ & Sig. \\
\hline (Constant) & & 0.285 & & 0.000 & & 0.019 \\
\hline Undergrad GPA & 0.149 & 0.178 & 0.350 & 0.003 & 0.135 & 0.161 \\
\hline Undergrad Major & -0.096 & 0.422 & 0.139 & 0.277 & -0.181 & 0.069 \\
\hline Work Years & 0.106 & 0.357 & 0.158 & 0.188 & 0.083 & 0.415 \\
\hline GMAT-Q \% & 0.058 & 0.643 & 0.253 & 0.070 & 0.221 & 0.044 \\
\hline GMAT-V\% & -0.158 & 0.176 & 0.087 & 0.474 & 0.039 & 0.711 \\
\hline Undergrad School & 0.152 & 0.169 & -0.022 & 0.847 & -0.158 & 0.113 \\
\hline Quarter & 0.052 & 0.639 & & & 0.276 & 0.006 \\
\hline \multirow[t]{4}{*}{ Gender X Distance } & 0.065 & 0.567 & 0.122 & 0.348 & 0.071 & 0.494 \\
\hline & $\mathrm{F}$ & 1.024 & $\mathrm{~F}$ & 3.141 & $\mathrm{~F}$ & 3.421 \\
\hline & $\mathrm{R}^{2}$ & 0.086 & $\mathrm{R}^{2}$ & 0.268 & $\mathrm{R}^{2}$ & 0.241 \\
\hline & Sig & 0.425 & Sig & 0.007 & Sig & 0.002 \\
\hline
\end{tabular}

Research Question 3: Do the demographic variables of Years of Work Experience, GMAT score, Undergraduate GPA, Undergraduate Major, Undergraduate School, etc. contribute to predicting student outcomes?

As indicated in Table 3, there was limited support for the impact of demographic variables as a predictor of outcomes. Only four of a potential 18 relationships were significant. For instance, undergraduate GPA was a significant predictor for the essay-based class $(\mathrm{p}=.006)$, while it remained insignificant for the case-based and quantitative courses $(\mathrm{p}=.243 \& \mathrm{p}=.188$, respectively). Similarly, undergraduate major was a significant predictor for the quantitative course ( $\mathrm{p}=.032$ ) but not for the case-based and essay-based courses ( $\mathrm{p}=.718 \& \mathrm{p}=.373$, respectively). Finally, GMAT Q\% was a useful predictor for the quantitative course ( $\mathrm{p}=.017)$, moderately significant for the essaybased course ( $\mathrm{p}=.074)$, and not significant for the case-based course $(\mathrm{p}=.735)$. While not confirmed in this sample, age has been found to be a positive predictor of success in distance learning programs (Neal, 1999).

Research Question 4: Does the distance delivery process differentially affect learning outcomes in the alternative types of course material presented in various elements of an MBA program - from the quantitative skills classes to the "soft skills" classes?

In each of the regression models presented in Table 3, the distance delivery variable was not statistically significant, indicating that the asynchronous distance delivery medium had no effect on student learning outcomes, regardless of the type of class analyzed. Whether the student was taking an organizational change class or a quantitative methods class, the distance delivery method had no measurable negative affect on the student's performance. It thus appears that this medium can be successfully used across the variety of courses studied here without fear of having a negative impact on these students.

\section{DISCUSSION}

\section{Limitations of the Present Study}

Some methodological issues will limit the generalizability of these findings. Most importantly, we have limited criterion variables. While measuring competencies with tests and papers is traditional, it may not be ideal. Certainly one of the larger limitations to this approach is the implicitly finite nature of the graded material, whether 
an exam or term paper. The exam may never capture completely what is expected of the student (Farber, 1998). Additionally, the courses contained in this study were exclusively business school oriented. This same study conducted on a much larger level, across a variety of colleges and content domains would provide richer evidence for the conclusions drawn here.

Another issue to explore is the absence of any attitudinal measures. It would have been useful to see if the attitudes towards the learning environment would have predicted student outcomes. And similar to this study, would attitudes about the whole distance education process be predictive of student outcomes? Finally, would student's attitudes regarding faculty competence be predictive of student outcomes?

It would have been interesting to randomly assign students to sections to thoroughly address potential confounds to external validity. Given that all of students in this study chose the environment in which they studied (rather than being randomly assigned to the on-campus or distance learning groups), our sample will have some selectivity issues. However, it is not possible to physically relocate distance students on-campus, or to ship the oncampus students away. This issue is one which is present in all studies that examine actual student performance in such environs. (Merisotis \& Phipps, 1999).

\section{Implications for Practice}

Many business school administrators are seeing a shift away from the traditional MBA program delivery paradigm. Repeatedly constructing more buildings may no longer be the best option for resource constrained institutions who want to continue serving more people. Even the weekend or evening programs may not be convenient enough for many MBA candidates, particularly ones who are increasingly technologically savvy. Developing alternate program delivery models that support distance learning can help serve new groups of students, and achieve demonstrably equivalent learning outcomes. Failure to do so may make some Business School programs increasingly less competitive with more technologically innovative alternative providers of educational services.

While there is expected to be another spike in traditional age students in the coming years, this does not mean that the traditional face-to-face model in higher education will re-emerge. Rather, it may serve as an expansion opportunity for universities that take the plunge (or expand existing operations) into a distance-learning program rather than spend precious capital on new buildings for students. One trend that is well under way is that traditional age students are opting to mix campus-based classes with online/distance courses (AACSB, 1999; Kirk \& Bartelstein, 1999).

Hickman (1999) highlights another mandate facing higher education institutions, that distance education methods can help address:

"...it has to become an integrated mission in public institutions to service all interested segments of the population... adequate partnerships need to be established to provide diversity of resources to the public" (p.19)

This idea of "access for the public" resonates throughout the literature on distance education (Merisotis \& Phipps, 1999). Distance education can provide a cost-effective means of delivering quality education. Where distance education programs were once the poor stepchild of the higher education family, they are now taking their place at the table with the other more traditional educational offerings. In order to promote distance education programs, they must be accorded the same prestige and dignity given to the traditional programs at the same institutions (Neal, 1999). They must also be provided the support staff necessary to handle any crises as they arise (Potashnik \& Capper, 1998).

It is important for educators to understand that not all potential students make good distance-education students. The distance program will require more self-confidence, more self-direction, and more self-efficacy than any other points. Students must be self-motivated (Lozada, 1997) and willing to learn the technology platform that serves as the backbone to service delivery. In this sample, we found that the being a distance education student did 
not significantly impact student performance. Several other variables (e.g. Undergraduate GPA, Undergraduate Major, GMAT-Q\%, etc.) did make a difference. The lack of an influence of years of work experience does support studies (e.g., Dreher \& Ryan, 2000) that find that previous work experience may have only a small impact on student performance and only in the initial period of a student's program of study. Because there was a difference between courses as to what demographic variable were significant it is appropriate to conclude that a "one size fits all" approach to selecting students is probably not appropriate. The evidence found here does suggest that using an asynchronous distance education approach is not an inhibitor to success across the gamut of different courses typically found in graduate business programs.

\section{REFERENCES}

1. AACSB. (1999). "Fifteenth Annual AACSB/UCLA Computer Usage Survey". Newsline. Winter. at http://www.aacsb.edu/Publications/Newsline

2. Adams, A. \& Hancock, T. (2000). "Work experience as a predictor of MBA performance". College Student Journal, 34(2), 211-216.

3. Barket, R. \& Holley, C. (1996). "Interactive distance learning: Perspective and thoughts". Business Communication Quarterly, 59 (4), 88-97.

4. Blumenstyk, G. (1997). "A feminist scholar questions how women fare in distance education". The Chronicle of Higher Education, 44(10), A36.

5. Blumenstyk, G. (1999a). "In a first, the North Central Association accredits an on-line university". The Chronicle of Higher Education, 45(28), A27

6. Blumenstyk, G. (1999b). "The marketing intensifies in distance learning". The Chronicle of Higher Education, 45(31), A31.

7. Burton, Jr., R. (1998). "Costs and benefits of increasing access to a traditional agricultural economics course". American Journal of Agricultural Economics, 80, 979-984.

8. Clark, T. \& Verduin, J. (1989). "Lifelong learning: An omnibus of practice and research". View, 12,(4), 2426.

9. Caudill, S. \& Gropper, D. (1991). "Test structure, human capital, and student performance on economics exams". The Journal of Economics Education, 22, 303-306.

10. Davey, K. (1999). "Distance learning demystified". National Forum, 79(1), 44-46.

11. Dreher, G., \& Ryan, K. (2000). "Prior work experience and academic achievement among first-year MBA students". Research in Higher Education, 41, 505-525.

12. Dubois, J. (1996). "Going the distance: A national distance learning initiative". Adult Learning, 8(1), 1921.

13. Farber, J. (1998). "The third circle: On education and distance learning". Sociological Perspectives, 41, 797.

14. Guerrero, L., \& Miller, T. (1998). "Associations between nonverbal behaviors and initial impressions of instructor competence and course content in videotaped distance education courses". Communication Education, 47(1), 30-42.

15. Harris, D. (1999). "Online education in the United States". IEEE Communications, 37(3), 87-93.

16. Hawkes, M. (1996). "Criteria for evaluating school-based distance education programs". NASSP Bulletin, 80(581), 45-52.

17. Hancock, T. (1999). "The gender difference: Validity of standardized admission tests in predicting MBA performance". Journal of Education for Business, 75(2), 91-94

18. Hickman, C. (1999). "Public policy: Implications associated with technology assisted distance learning". Adult Learning, (Spring), 17-21.

19. Holmberg, B. (1985). "On the status of distance education in the world in the 1980's: A preliminary report on the fernuniversitat comparative study". Zentrales Inst. Fur Fernstudienforschung Arbeitsberich, 1-34.

20. Kirk, E., \& Bartelstein, A. (1999). "Libraries close in on distance education". Library Journal, 124(6), 40.

21. Koch, J. (1998). "How women actually perform in distance education". The Chronicle of Higher Education, 45(3), A60.

22. Lenzner, R (1997, March 10). "Seeing things as they really are". Forbes, 59, 122-128.

23. Lozada, M. (1997). "Look out for distance learning". Techniques, 72(7). 24-26. 
24. Merisotis, J., \& Phipps, R. (1999). "What's the difference?” Change, 31(3), 12-17.

25. National Center for Education Statistics. (1998, February). Distance Education in Higher Education Institutions: Incidence, Audiences, and Plans to Expand.

26. Potashnik, M., \& Capper, J. (1998). "Distance education: Growth and diversity". Finance \& Development, $35(1), 42-45$.

27. The Institute for Higher Education Policy. (1999, February). Distance Learning in Higher Education.

28. Russell, T. (1998). "The no significant difference phenomenon". Http://cuda.teleeducation.nb.ca/ nosignificantdifference/

29. Thayer, P., \& Khalat, J. (1998). "Questionable criteria". American Psychologist, 53(5), 566-570.

30. Walling, L. (1996). "Going the distance: Equal education, off campus or on". Library Journal, 121(20), 5962 .

31. Wang, A. \& Newlin, M. (2000). "Characteristics of students who enroll and succeed in psychology webbased classes". Journal of Educational Psychology, 92, 137-143.

32. Webster, J, \& Hackley, P. (1997). "Teaching effectiveness in technology-mediated distance learning". Academy of Management Journal, 40, 1282-1307.

$\underline{\text { Notes }}$ 